\title{
Emergency peripartum hysterectomy at a tertiary care hospital: analysis of epidemiology, clinical profile, indications and outcome
}

\author{
Anitha E., Ramalakshmi S.*
}

Department of Obstetrics and Gynecology, Tirunelveli Medical College Hospital, Tirunelveli, Tamil Nadu, India

Received: 11 March 2019

Accepted: 15 March 2019

\section{*Correspondence:}

Dr. Ramalakshmi S.,

E-mail: ograma60@gmail.com

Copyright: () the author(s), publisher and licensee Medip Academy. This is an open-access article distributed under the terms of the Creative Commons Attribution Non-Commercial License, which permits unrestricted non-commercial use, distribution, and reproduction in any medium, provided the original work is properly cited.

\section{ABSTRACT}

Background: Peripartum hysterectomy is a life-saving obstetric procedure that is performed at the time of a caesarean section or postpartum following either vaginal delivery or caesarean section. The purpose of the present study was to determine the incidence, risk factors ,indications ,maternal and neonatal morbidity, mortality and complications of emergency peripartum hysterectomy performed at a tertiary teaching hospital in South India and to compare the results with other reports in literature.

Methods: During the period of study between January 2015-December 2016, there were 50 cases of emergency peripartum hysterectomy at Tirunelveli medical college hospital, Tirunelveli, Tamil Nadu, South India. Medical, pathology and operation theatre records were analyzed retrospectively. Details of maternal age, parity, booking status, underlying risk factors, past obstetric history, gestational age at delivery ,mode of delivery ,indications for emergency peripartum hysterectomy, type of operation, intraoperative and post-operative complications, blood components transfusion ,maternal and neonatal outcomes were noted and analyzed.

Results: During the 2-year study period there were 50 emergency peripartum hysterectomy out of 14,363 deliveries, a rate of 1 per 294 deliveries (3.4/1000 deliveries). $80 \%$ of hysterectomies were performed after caesarean delivery and $20 \%$ after vaginal delivery. The two major indications were abnormal placentation $(40 \%)$ and uterine atony (28\%). There were 6 maternal deaths among patients who underwent emergency peripartum hysterectomy during the period of study.

Conclusions: Improved antenatal care, correction of anaemia, identification of risk factors for peripartum hysterectomy, timely referral, expedite management, timely decision, availability and liberal use of blood components and appropriate management of post-operative complications by experienced clinical team are the main stay for saving maternal lives. With increasing rate of caesarean section there is rise in the incidence of abnormal placentation.

Keywords: Abnormal placentation, Emergency peripartum hysterectomy, Incidence, Indications, PPH, Risk factors

\section{INTRODUCTION}

Emergency Peripartum hysterectomy is a life-saving obstetric procedure that is performed at the time of caesarean section or postpartum following either vaginal delivery or caesarean section. ${ }^{1-3}$ The first reported case of caesarean sub- total hysterectomy was performed in $1876 .^{4}$ It is performed for life threatening obstetric haemorrhage where all conservative methods have failed and in order to save a maternal life. There has been a change in the main indications of emergency peripartum hysterectomies in recent years. ${ }^{2}$ Abnormal placentation which includes placenta praevia and morbidly adherent placenta has now become the major indication followed by uterine atony and rupture uterus. Increasing rate of caesarean deliveries over the past few decades also better conservative management of atonic uterus and reduced incidence of rupture uterus due to extensive use of lower 
segment caesarean section have been the main reason for recent change in the most frequent indication. Studies have shown that the risk of emergency peripartum hysterectomy increases with the number of caesarean sections.

Emergency peripartum hysterectomy being a radical surgical procedure done to save the life of a mother when all conservative methods have failed to control haemorrhage, it is essential to balance the need for conservation of uterus for future fertility against the need for timely radical intervention to save a life.

The purpose of the present study was to determine the incidence, risk factors, indications, maternal and neonatal morbidity, mortality and complications of emergency peripartum hysterectomy performed at a tertiary teaching hospital in Tamil Nadu and to compare the results with other reports in literature.

\section{METHODS}

Details of maternal age, parity, booking status, risk factors, past obstetric history, history of present pregnancy, mode of delivery, indications for emergency peripartum hysterectomy type of operation, intra operative and post-operative complications ,blood components transfusion, duration of hospital stay, maternal and neonatal outcomes of 50 patients who underwent emergency Peripartum hysterectomy between Jan 2015-Dec 2016 at Tirunelveli medical college hospital, Tirunelveli, Tamil Nadu were noted from hospital medical records and cross checked with operation theatre records and pathology reports . The data was meticulously analyzed. All women received conservative medical and surgical intervention to control severe obstetric haemorrhage before the decision to perform peripartum hysterectomy. The decision to perform an emergency peripartum hysterectomy was taken after all other medical and conservative surgical methods have failed. The procedure was performed by senior obstetrician and team .All deliveries were performed after 28 weeks of gestation .Maternal complications such as hemorrhagic, urological, infectious, respiratory, renal, thromboembolic complications and maternal death were also recorded. Frequencies and percentages were recorded as descriptive statistics.

\section{RESULTS}

\section{Incidence}

During the 2 year study period a total of 14,363 deliveries occurred at our hospital. There were 50 emergency peripartum hysterectomies giving an incidence of $0.34 \%$ (3.4/1000) i.e. 1 in 294 deliveries. This incidence although comparable to developing countries was much higher than developed countries.

\section{Maternal characteristics}

\section{Age distribution of pregnant women}

Table 1 signifies the age distribution of pregnant women. There were $9(18 \%)$ patients in the age group 21-25 years. $28(56 \%)$ patients were in the age group of $26-30$ years $.9(18 \%)$ patients were in the age group 31-35 years between $36-40$ years there were $3(6 \%)$ patients. one $(2 \%)$ patient was more than 40 year. Higher incidence was found in age group 26-30 years. The mean age of patients was 29.96 years.

Table 1: Age distribution of pregnant women.

\begin{tabular}{|l|l|l|}
\hline Age group & Number of patients & Percentage \\
\hline $21-25$ & 9 & 18 \\
\hline $26-30$ & 28 & 56 \\
\hline $31-35$ & 9 & 18 \\
\hline $36-40$ & 3 & 6 \\
\hline$>40$ & 1 & 2 \\
\hline Mean age (years) & 29.96 & \\
\hline
\end{tabular}

\section{Demographic data of pregnant women}

Table 2 shows maximum number of women were multiparous $92 \%$. While $8 \%$ of hysterectomies were in primigravidas

Table 2: Demographic profile of pregnant women.

\begin{tabular}{|l|l|l|}
\hline Parameter & Parity (number) & Percentage \\
\hline Primi & 4 & 8 \\
\hline Multi & 46 & 92 \\
\hline
\end{tabular}

\section{Gestational age at delivery}

Table 3 shows the period of gestation of pregnant who underwent EPH. Maximum number of patients $31(62 \%)$ were found in term gestation between 37-40 weeks $.19(38 \%)$ patients who underwent EPH delivered prematurely i.e. GA<36 weeks. All patients had EPH $>28$ weeks gestational age. Higher incidence was found at term gestation.

Table 3: Period of gestation of pregnant women.

\begin{tabular}{|l|l|}
\hline Gestational age( weeks) & No. (Percentage) \\
\hline $28-36$ & $19(38 \%)$ \\
\hline $37-40$ & $31(62 \%)$ \\
\hline
\end{tabular}

\section{Mode of delivery}

Among 50 patients who underwent EPH ,10 (20\%) patients delivered vaginally, while $40(80 \%)$ patients delivered by caesarean section. Maximum number of patients underwent EPH following caesarean section. Among caesarean section 12 patients had elective LSCS, 
while 28 patients had emergency caesarean section. All patients had elective LSCS indicated for placenta praevia.

\section{Indications for $\mathrm{EPH}$}

Abnormal placentation (40\%) and uterine atony (28\%) were the two major indications for EPH. Other indications include rupture uterus (18\%), sepsis (2\%) and traumatic PPH (12\%) (Table 4).

\section{Table 4: Indications for EPH.}

\begin{tabular}{|l|l|l|}
\hline Indications & No. of patients & Percentage \\
\hline Abnormal placentation & 20 & 40 \\
\hline Uterine atony & 14 & 28 \\
\hline Rupture uterus & 9 & 18 \\
\hline Sepsis & 1 & 2 \\
\hline Traumatic PPH & 6 & 12 \\
\hline
\end{tabular}

\section{Risk factors for EPH}

Table 5 shows the analysis of risk factors that predisposed to EPH in our patients. Most common risk factor associated with more than half of our cases (58\%) was previous scarred uterus. Most of the cases of previous LSCS was complicated by placenta praevia(34\%).Other risk factors include anaemia(18\%), gestational hypertension(16\%), multiparity(6\%). Certain associated factors like multiple gestation (2\%), gestational diabetes (2\%), medical disorders (6\%) and abruption placentae $(4 \%)$ were also noted.

Table 5: Risk factors for EPH.

\begin{tabular}{|l|l|l|}
\hline Risk factors & Number & Percentage \\
\hline Previous LSCS/myomectomy & 29 & 58 \\
\hline Multiparity & 3 & 6 \\
\hline Multiple gestation & 1 & 2 \\
\hline GHT & 8 & 16 \\
\hline GDM & 1 & 2 \\
\hline Medical disorders & 3 & 6 \\
\hline Placenta praevia & 17 & 34 \\
\hline Abruption & 2 & 4 \\
\hline Anaemia & 9 & 18 \\
\hline
\end{tabular}

\section{Type of operation and additional surgical procedures}

Among 50 cases of EPH observed in the study period , $48(96 \%)$ were total hysterectomies,2(4\%) cases were subtotal hysterectomies.8(16\%) of patients had internal iliac artery ligation and B-Lynch suturing .2 patients required repair for bladder injury and one patient had repair for bowel injury. Almost all patients had $>2$ units of blood components transfusions.

\section{Incidence of maternal morbidity and mortality}

There were $6(12 \%)$ cases of maternal death among 50 cases of EPH which contributed to $9 \%$ of overall maternal deaths during the study period. Causes of maternal death include irreversible shock, DIC, multiorgan failure and sepsis. Most of the cases were referred either late in term with risk factors or intrapartum and following delivery in moribund state (Table 6).

Table 6: Maternal morbidity.

\begin{tabular}{|l|l|}
\hline Maternal morbidity & No. (Percentage) \\
\hline Febrile complications & $10(20)$ \\
\hline DIC & $7(14)$ \\
\hline Anaemia & $5(10)$ \\
\hline Sepsis & $2(4)$ \\
\hline Liver failure & $2(4)$ \\
\hline AKI & $3(6)$ \\
\hline Cerebral complications & $2(4)$ \\
\hline Shock & $4(8)$ \\
\hline Thrombocytopenia & $5(10)$ \\
\hline Ventilator related complications & $3(6)$ \\
\hline Bladder injury & $2(4)$ \\
\hline Relaparotomy & $2(4)$ \\
\hline Wound infection & $1(2)$ \\
\hline Bowel injury & $1(2)$ \\
\hline
\end{tabular}

\section{Neonatal outcome}

Among 50 cases in present study period, 31 cases delivered at term and 19 delivered preterm. There were 9 stillbirths of which 2 were term babies and 7 preterm babies.

\section{DISCUSSION}

\section{Comparative analysis of emergency peripartum hysterectomy}

Emergency peripartum hysterectomy is performed in the management of life threatening obstetric haemorrhage not controlled by conventional medical and surgical methods. In the present study conducted over a period of two years among 14,363 deliveries during that period there were 50 cases of EPH with an overall incidence of $0.34 \%(3.4 / 1000)$ i.e. 1 per 294 deliveries. In present study the majority of patients who underwent EPH were in the 26-30 years (56\%) age group and higher incidence was noted in multipara (92\%). All cases were booked.

In modern obstetrics, the incidence of $\mathrm{EPH}$ is $0.05 \%$, but there are considerable differences in incidence in developed and developing countries, depending on available obstetric services, standards and utilization of antenatal care, and the effectiveness of family planning services of a given population. The incidence of peripartum hysterectomy in the literature is reported as $0.24,0.77,2.3$, and 5.09 per 1,000 deliveries by Sakse et al.5 , Whiteman et al., Bai et al. and Zeteroglu et al, respectively. ${ }^{5-9}$ In the United States, it is performed in 0.05 to 0.1 percent of all deliveries and 0.5 percent of 
cesarean deliveries and similar results have been reported also in Canada and in Europe(Bodelon.C et al). ${ }^{9}$ In India the reported incidence is in the range of $0.04 \%$ to $0.35 \%$. Two studies from India Chawla et al and Rashmi $\mathrm{MB}$ et al reported $0.08 \%$ rate of $\mathrm{EPH}$. Our incidence of $0.34 \%(3.4 / 1000)$ i.e. 1 per 294 deliveries is higher than the reported incidence. ${ }^{10,11}$ The rate of EPH in a study by Ohonsiet al in Nigeria, was 4.0 per 1000 deliveries. $^{12}$ In the present study, $10(20 \%)$ patients delivered vaginally and $40(80 \%)$ patients delivered by caesarean section among 50 cases of EPH. Maximum number of patients underwent EPH following caesarean section. Among caesarean section 12 patients had elective LSCS ,while 28 patients had emergency caesarean section. All cases of elective caesarean section was done for placenta praevia. Lovina SM. Machado reported a similar trend of emergency peripartum hysterectomy to be more common following cesarean section than vaginal deliveries. ${ }^{13}$ In a study by Engelsen IB et al Eight women had a cesarean section and three women had a spontaneous vaginal delivery among 11 cases of EPH. Higher incidence of cases of EPH were following caesarean section. ${ }^{14}$

The most frequent indication for peripartum hysterectomy in the present study was abnormal placentation(40\%) followed by uterine atony (28\%), rupture uterus (9\%), traumatic PPH (12\%)and sepsis(2\%)].This is attributed to the higher incidence of primary caesarean section rates and abnormal placentation in subsequent pregnancies. A study by L. M. Stanco et al, stated their common indication was abnormal placentation followed by uterine atony.Lovina S.M. Machado also noted the predominant indication for emergency peripartum hysterectomy was abnormal placentation (placenta praevia / accreta) which was noted in 45 to $73.3 \%$, uterine atony in 20.6 to $43 \%$ and uterine rupture in 11.4 to $45.5 \% .^{13,15}$ Baskett reported that the main indication for EPH was placenta accreta and atonic PPH. ${ }^{16}$ There has been a significant change in the indication of EPH over time and from one region to another. Traditionally, uterine atony was the most common indication for hysterectomy. Recent studies have indicated that abnormal placentation is replacing uterine atony as the most common indication for EPH. In institutions with lower rate of caesarean section atonic PPH remain the most common indication. ${ }^{17,18}$

Most common risk factor associated with more than half of our cases $(58 \%)$ was previous scarred uterus .Most of the cases of previous LSCS was complicated by placenta praevia $(34 \%)$. Other risk factors noted include anaemia (18\%), gestational hypertension (16\%), multiparity $(6 \%)$. Certain associated factors like multiple gestation $(2 \%)$, gestational diabetes (2\%), medical disorders (6\%)and abruption placentae $(4 \%)$ were also noted. These findings were similar to cases reported in literature. ${ }^{19}$ The risk factors included previous cesarean section, scarred uterus, multiparity, older age group. Other risk factors for EPH like abnormal placental invasion, uterine atony, rupture uterus, previous caesarean section, induced labour and current caesarean delivery were similar to statistics reported in literature. EPH is associated with higher complication rate due to massive transfusions, DIC, relaparotomy febrile complications. ${ }^{19,20,21}$ The maternal morbidity ranged from 26.5 to $31.5 \%$ and the mortality from 0 to $12.5 \%$ with a mean of $4.8 \% .^{13} \mathrm{EPH}$ is associated with high maternal morbidity mainly due to massive transfusions, DIC ,injury to urinary tract, relaparotomy and febrile morbidity. All our patients received blood component transfusions of more than 2 units .

The urinary tract injury rate in present study is $4 \%$, as compared to Smith's 6\%, Kwee's 15\%, Yucel's 8.8\%, Zeteroglu's 12.5\%, Zelop's 9\%, and Ferreira's $7.7 \% .^{18,21-23}$ Relaparotomy was performed in 2 (4\%)cases of EPH in present study compared with kwee's $25 \%$ and ozden's $6.8 \% .{ }^{17}$ In present study 7 patients (14\%) developed DIC much lower than 33\% rate reported by Smith and Mousa and Lau et al. ${ }^{19,22}$ Maternal death rate was $12 \%$ in present study. Lower rates of $4,4.5 \%$ and $7.7 \%$ were cited by Kwee et al. ${ }^{2}$ Zorlu et al, Ferreira et al respectively and much higher rates of 20 and $23.8 \%$ were noted by Hamsho and Alsakka and Umezurike et al. ${ }^{18,20,24-26}$

\section{CONCLUSION}

Emergency peripartum hysterectomy is a life saving obstetric procedure but timely decision and management by an experienced senior obstetric team is essential to avoid maternal mortality. The factors responsible for higher incidence of obstetric hysterectomy in the developing countries are low socioeconomic status, poverty, lack of awareness, poor transportation facilities, unscientific deep rooted cultural and religious beliefs, high incidence of unbooked pregnancies and poorly supervised deliveries. All obstetricians should be trained to perform this life saving procedure. Good antenatal care, identification of risk factors, institutional delivery, antenatal correction of anaemia, timely referral, easy availability of transport, anticipating PPH in high risk groups, good post-operative care, wide availability of blood and components transfusion facilities, better postoperative intensive care can contribute to the reduction in the incidence of maternal morbidity and maternal mortality. Improvement in socio-economic conditions, community education, better nutrition, access to and utilization of antenatal services, refresher courses for ANM's, staff nurses, medical officer's at PHC's, upgrading of PHC's, better transport facilities, adequate manpower and family planning practices can improve maternal and neonatal outcome. Being the most common risk factor noted, Caesarean section rate should be brought down.

Funding: No funding sources

Conflict of interest: None declared

Ethical approval: The study was approved by the Institutional Ethics Committee 


\section{REFERENCES}

1. Rossi AC, Lee RH, Chmait RH. Emergency postpartum hysterectomy for uncontrolled postpartum bleeding:a systematic review. Obstet Gynecol. 2010;115(3);637-44.

2. Kwee A, Bots ML, Visser GH, Bruinse HW. Emergency peripartum hysterectomy: a prospective study in The Netherlands. European Journal of Obstet Gynecol Reproduct Biol. 2006;124(2):18792.

3. Akar ME, Yilmaz ES, Yuksel B, Yilmaz Z. Emergency peripartum hysterectomy. Europe J Obstet Gynecol Reproduct Biol. 2004 Apr 15;113(2):178-81.

4. Sturdee DW, Rushton DI. Caesarean and postpartum hysterectomy 1968-1983. BJOG: An Int J Obstet Gynaecol. 1986;93(3):270-4.

5. Sakse A, Weber T, Nickelsen C, Secher NJ. Peripartum hysterectomy in Denmark 1995-2004. Acta Obstet et Gynecol Scandinavica. 2007;86(12):1472-5.

6. Whiteman MK1, Kuklina E, Hillis SD, Jamieson DJ, Meikle SF, Posner SF, et al Incidence and determinants of peripartum hysterectomy. Obstetrics and Gynecology, Obstet Gynecol. 2006;108(6):148692.

7. Bai SW, Lee HJ, Cho JS, Park YW, Kim SK, Park KH. Peripartum hysterectomy and associated factors. J Reproduct Med. 2003;48(3):148-52.

8. Zeteroglu S, Ustun Y, Engin-Ustun Y, Sahin G, Kamac1 M. Peripartum hysterectomy in a teaching hospital in the eastern region of Turkey. Europe $\mathbf{J}$ Obstet Gynecol Reproduct Biol. 2005;120(1):57-62.

9. Bodelon C, Bernabe-Ortiz A, Schiff MA, Reed SD. Factors associated with peripartum hysterectomy. Obstet Gynecol. 2009;114(1):115-23.

10. Chawla J, Arora C, Paul M, Ajmani S. Emergencyobstetric hysterectomy: a retrospective study from teaching Hospital in North India over Eight Years. Oman Med J. 2015;30(3):181-6.

11. Rashmi MB, Rajkumari. Emergency Peripartum Hysterectomy: A 3-Year Review. IJCMAASE. 2015;6(1):60-3.

12. Omole-Ohonsi A, Taiwo Olayinka H. Emergency Peripartum Hysterectomy in a Developing Country: J Obstet Gynaecol Can. 2012;34(10):954-60.

13. Lovina S.M. Machad Emergency peripartum hysterectomy: Incidence, indications, risk factors and outcome N Am J Med Sci. 2011;3(8):358-61

14. Engelsen IB, Albrechtsen S, Iversen OE. Peripartum hysterectomy-incidence and maternal morbidity. Acta Obstet Et Gynecol Scandinavica. 2001;80(5):409-12.
15. Stanco LM, Schrimmer DB, Paul RH, Mishell Jr DR. Emergency peripartum hysterectomy and associated risk factors. Am J Obstet Gynecol. 1993;168(3):87983.

16. Baskett TF. Emergency obstetric hysterectomy. J Obstet Gynaecol. 2003;23(4):353-5.

17. Özden S, Yildirim G, Basaran T, Gurbuz B, Dayicioglu V. Analysis of 59 cases of emergent peripartum hysterectomies during a 13-year period. Arch Gynecol Obstet. 2005;271(4):363-7.

18. Ferreira Carvalho J, Cubal A, Torres S, Costa F, Carmo OD. Emergency peripartum hysterectomy: A 10-year review. ISRN Emergency Medic. 2012;2012

19. Lau WC, Fung HY, Rogers MS. Ten years experience of caesarean and postpartum hysterectomy in a teaching hospital in Hong Kong. Europe J Obstet Gynecol and Reproduct Biol. 1997;74(2):133-7.

20. Chestnut DH, Eden RD, Gall SA, Parker RT. Peripartum hysterectomy: a review of cesarean and postpartum hysterectomy. Obstet Gynecol. 1985;65(3):365-70.

21. Zelop CM, Harlow BL, Frigoletto Jr FD, Safon LE, Saltzman DH. Emergency peripartum hysterectomy. Am J Obstet Gynecol. 1993;168(5):1443-8.

22. Smith J, Mousa HA. Peripartum hysterectomy for primary postpartum haemorrhage: incidence and maternal morbidity. J Obstetrics Gynaecol. 2007;27(1):44-7.

23. Yucel O, Ozdemir I, Yucel N, Somunkiran A. Emergency peripartum hysterectomy: a 9-year review. Archives of gynecology and obstetrics. 2006;274(2):84-7.

24. Zorlu CG, Turan C, Işik AZ, Danişman N, Mungan $\mathrm{T}$, Gökmen O. Emergency hysterectomy in modern obstetric practice changing clinical perspective in time. Acta Obstetricia Et Gynecologica Scandinavica. 1998;77(2):186-90.

25. Hamsho MA, Alsakka M. Emergency obstetric hysterectomy in Qatar--a 20-year review. Int J Fertil Women's Med. 1999;44(4):209-11.

26. Umezurike CC, Paul A, Adisa CA. Peripartum hysterectomy in Aba southeastern Nigeria. Aus NZ J Obstet Gynaecol. 2008;48(6):580-2.

Cite this article as: Anitha E, Ramalakshmi S.

Emergency peripartum hysterectomy at a tertiary care hospital: analysis of epidemiology, clinical profile, indications and outcome. Int J Reprod Contracept Obstet Gynecol 2019;8:1308-12. 